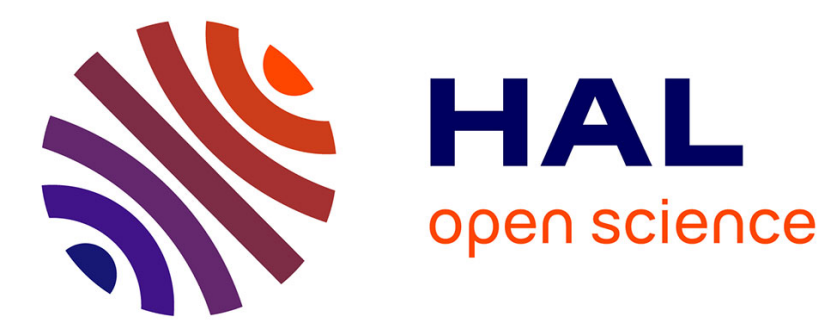

\title{
Studying work practices: a key factor in understanding accidents on the level triggered by a balance disturbance
}

Carine Derosier, Sylvie Leclercq, Pierre Rabardel, P. Langa

\section{To cite this version:}

Carine Derosier, Sylvie Leclercq, Pierre Rabardel, P. Langa. Studying work practices: a key factor in understanding accidents on the level triggered by a balance disturbance. Ergonomics, 2008, 51 (12), pp.1926-1943. 10.1080/00140130802567061 . hal-01578559

\section{HAL Id: hal-01578559 \\ https://hal.science/hal-01578559}

Submitted on 29 Aug 2017

HAL is a multi-disciplinary open access archive for the deposit and dissemination of scientific research documents, whether they are published or not. The documents may come from teaching and research institutions in France or abroad, or from public or private research centers.
L'archive ouverte pluridisciplinaire HAL, est destinée au dépôt et à la diffusion de documents scientifiques de niveau recherche, publiés ou non, émanant des établissements d'enseignement et de recherche français ou étrangers, des laboratoires publics ou privés. 


\title{
Studying work practices: a key factor in understanding accidents
} on the level triggered by a balance disturbance

\section{DEROSIER ${ }^{1,2 *}$, S. LECLERCQ $^{1}$, P. RABARDEL ${ }^{2}$ and P. LANGA ${ }^{2}$}

${ }^{1}$ French National Research and Safety Institute (INRS), Working Life Department Biomechanics and Ergonomics Laboratory Avenue de Bourgogne, BP 27, 54501 Vandoeuvre, France

\author{
${ }^{2}$ Paris VIII University
}

Cognition Language Interaction Doctoral School, Paragraphe Laboratory

2, Rue de la Liberté

93526 Saint Denis Cedex 2, France

* Corresponding author. Email : carine.derosier@inrs.fr 
Statement of relevance. AOL are serious and frequent in occupational situations. Injury claims analysis and interviews in an industrial company emphasise the specific characteristics of an occupational situation and of prevention actions forming the basis of an intervention. The need for a better understanding of factors affecting work practice is highlighted in relation to research. 


\section{Abstract}

Accidents on the level (AOL) rank second amongst the most numerous and serious occupational accidents (OA) with days lost in France and are a major health and safety problem in every sector of activity.

The case study described in this paper was conducted at a metallurgical company with 300 employees. The aims of this work were dual: to extend the general knowledge required for preventing these accidents and to propose prevention measures to this company. Existing data on company occupational accidents were gathered and analysed to identify a work situation which appeared likely to cause AOL. This work situation was analysed in details. Several risk factors were identified within this work situation, by way of interviews with twelve operators. These risk factors concerned various dimensions of the work situation, particularly its physical dimension (e.g. templates structure) and organisational dimension (e.g. parts availability). Interviews were conducted, focusing on risk factors perceived by operators and involving allo-confrontations based on accounts of four AOL occurring in this situation. Allo-confrontations were interviews confronting operators with a risk occupational situation which was accidental for one of their colleagues, the latter being absent from the interview. Results highlighted the fact that the work practices implemented are key factors in understanding these accidents. This study underlines the role of work practices in AOL causality and prevention. It also provides explanations associated with various work situation dimensions involving adoption of more or less safe work practices. AOL are serious and frequent in occupational situations. Injury claims analysis and interviews in an industrial company emphasise the specific characteristics of an occupational situation and of prevention actions forming the basis of an intervention. The need for a better understanding of factors affecting work practice is highlighted in relation to research.

Keywords: Injury prevention, Occupational accident, Accident on the level, Slips, trips and falls, Accident analysis, Work practices 


\section{Introduction}

Accidents on the level (AOL) occurring in a work situation represent a significant issue in occupational health and safety terms. French national statistics for year 2005 concern $17,878,256$ employees who were covered by the employee national health insurance system (CNAMTS, 2005). These statistics reveal that not only are these accidents subject to high frequency of occurrence ( $20 \%$ of all occupational injuries), but that they also have serious consequences (Leclercq and Tissot, 2004). Thus, a quarter of the days lost through temporary disability following an occupational accident (OA) are lost because of AOL. Despite the many technological advances witnessed during our century and the regression in certain categories of occupational accidents, the frequency of occurrence of AOL with days lost, with reference to the number of employees, has remained relatively unchanged for its part (Gaudez et al., 2006). Whilst the number of AOL has decreased over the years, the relative proportion of these accidents with respect to all occupational accidents with days lost has tended to rise: management of AOL risk would have therefore not followed that of other OA risks.

The terminology employed, when referring to these accidents, differs according to country and author [e.g. "slip, trip and fall" by Bentley and Haslam (UK, 1998, 2001); "accident on the level" by Leclercq (France, 2005); "underfoot accidents" by Manning et al. (UK, 1988,) and Davies et al. (UK, 2003)], but the data and statistics concur on their high ranking amongst occupational accidents (HSE, UK, 2007; Webster, US Department of Labor, 2000; Bowman, Australia, 2007). Most of the time, they are ranked second or third amongst the most frequent and most serious occupational accidents. The term "accident on the level" (AOL) will be used herein because this paper is concerned with accidents following balance disturbance, which does not systematically cause the victim to fall. Therefore, accidents in which protection 
against falls from a higher level must be provided are excluded. The definition that is adopted is as follows: an AOL is an "accident triggered by unexpected balance disturbance of the victim during work, which is not performed "at height". The victims recover their balance or fall; in either case, they sustain injuries. Both ground surfaces without changes of level and with changes of level, such as sidewalk kerbs, steps or slopes, are considered" (Leclercq, 2005).

This study is based on detailed analysis of a work situation identified as being likely to cause AOL occurrence and it takes into account various dimensions of this situation: environmental, physical, human and organisational. Whilst AOL are not generally considered specific to work situations, the literature describes factors explaining these accidents, which relate to all the above-mentioned dimensions [Bentley and Haslam (1998), Kines (2003), Leclercq, (1997, 2002)]. Nowadays, there are only few studies which have a systemic view on these accidents (Bentley, 2008), and which try, by using detailed analysis [Bentley et al. (2005, 2006), Derosier (2005), Gao and Abeysekera (2004), Leclercq and Thouy (2004)], to enlighten contributing factors and root causes involved in these accidents. Nevertheless, these studies underline the interactions between intrinsic factors such as age, tiredness, experience, attention (etc.) and extrinsic factors such as task, environment, work organisation (etc.), which are factors to be taken into account while proposing appropriate prevention actions (Gauchard et al., 2001).

The aims of this work are dual. The first aim is to understand why AOL occur in this situation and thus to be in a position to identify, jointly with the company, prevention measures specific to the situation. The second aim is to give direction to research aimed at extending knowledge required for preventing these accidents, occurring in work situations. 


\section{Method}

Selection of the company, at which our AOL study would be conducted, was undertaken in partnership with the regional health insurance fund (CRAM Nord Est). This body is notably in charge of recording occupational accidents, with days lost, occurring at companies covered by the general health insurance system for this region of North-Eastern France. The selected company was retained on the basis of both the number of AOL recorded for the personnel (30\% of recorded OA with days lost) and the feasibility of performing this study (notably the possibility of conducting interviews with operators inside their working shifts). The company manufactures skips, tanks and trailers for lorries (tractor units) and employs approximately 300 people. It performs mainly welding, cutting, assembly/erection and painting operations.

The selected company was a multi-trade company and AOL was a priori likely to occur in different contexts. Pre-existing OA data (mainly infirmary records) were collected and processed to identify the work situations likely to cause AOL occurrence in this company. An OA was considered to be an AOL when infirmary records referred to a gait disturbance (e.g. the victim fell down; the victim tripped; etc.). The collected information comprised the 82 AOL (with and without days lost) which occurred between the years 2002 to 2005 and, in particular, data related to both the locations, times and circumstances of OA occurrence and to the trades of victims. Data on accident locations (ten different buildings and outside), victims' jobs (sixteen different jobs) and circumstances (e.g. templates, pits, ground) were crossreferenced. It appeared that mechanical welding workshop, in which twelve "assemblerwelders" assembled chassis on templates was a work situation more likely to cause AOL. In this situation, four AOL occurred between 2002 and 2005 when operators were walking on 
templates (their feet slipped, tripped or missed chassis or template parts) or when they climbed onto or got down from the template. The assembler-welders moved around templates formed by large metal structures, approximately one metre high, for assembling lorry chassis parts. All twelve operators took part in the study, their ages ranging from 24 to 52 years.

Chassis assembly comprised several phases involving assembly of sets of parts for areas of the chassis (bumper, carriage sheet, suspension hands, etc.). The following work tasks were performed by an assembler-welder during these different assembly phases:

- Reading and understanding shop drawings and instructions;

- Collecting parts and tools required to assemble chassis;

- Assembling chassis (installation of different parts, scribing, triangulation);

- Possibly rectification of parts (cutting, butting together, straightening);

- Stitching (spot-welding) chassis members (figure 1).

These work tasks are globally performed following the chronological order presented above. In practice, there was some overlap and variability in these tasks: e.g. assembler-welders need to read shop drawings while assembling the chassis. On average, standard chassis assembly and welding took an operator ten hours. Of these ten hours, operators spent approximately three hours working on the template and, from time to time, needed to walk on more or less stable, narrow surfaces, and to climb onto, and down from, the template (approximately one meter high). These activities were challenging as far as operators' balance was concerned.

\section{[Insert FIGURE 1]}

Figure 1. Operator applying spot weld at joints between chassis cross-beams and edge, parts previously positioned on the template by this same operator. 
This systemic study demanded precise understanding of the assembly-welding activity and to ensure familiarity with trade "jargon". Methodology comprising two phases of personal interviews with the twelve assembler-welders. The aim of these interviews was to provide detailed data on the AOL risk and the four AOL, which had occurred in this work situation between 2002 and 2005.

The first phase comprised individual semi-directive interviews of the four operators who sustained an AOL. These interviews were divided into two stages. One stage aimed at identifying AOL risk factors perceived by operators in this work situation. A second stage aimed at consolidating information on each AOL so that illustrated accounts of the four accidents could be prepared photographically. The first stage began with an open question: operators were asked to talk about the AOL risk factors they had encountered in their work situation. A number of specific questions were then asked to provide more detail on these perceived risk factors and the way in which they were managed (e.g. "According to you, are these AOL risk factors foreseeable? If yes, thanks to which signs?" "According to you, what could be done to prevent AOL occurrence?").

The second stage of these interviews also began with an open question: operators were asked to talk about the AOL they had sustained. A number of directive questions were asked when information was missing in the AOL accounts (researchers tried to collect data about where, when, how and why these AOL occurred, and what were the consequences of the studied AOL). Following each individual interview, operator who sustained an AOL was invited to take photographs of the work station occupied by him at the time of his AOL for preparation of an illustrated account of the AOL sustained by the victim concerned. The four illustrated accounts are effectively written, image-supported reconstructions of the four AOL. The data they include concern locations and times of AOL occurrence, the operation performed before 
and at the time of the accident, factors considered usual or unusual by the victim during the accident event, carrying of tools and/or parts during balance disturbance and walking conditions in more general terms.

The second phase of this work comprised individual semi-directive interviews of eight colleagues of the operators who sustained an AOL. Two interview stages can again be distinguished. The format of first stage was identical to that of the four interviews of the AOL victims (identification of perceived AOL risk factors). Questions asked during this stage with the work colleagues were identical to those of the first stage conducted with the operators who sustained an AOL.

In the second interview stage, the eight colleagues commented on the AOL sustained by the four victims after being successively presented with the four illustrated AOL accounts. This stage was based on interviews called allo-confrontations. They involved "confronting participants with an activity they practice but which is performed by someone else, without the latter being present" (Mollo and Falzon, 2004). In this study, these interviews confronted operators with a risk situation experienced during work and which was accidental for one of their colleagues, who was absent from the interview. An accident is, by nature, a nonobservable past event, so the illustrated accident accounts represented an alternative tool describing the victim's activity before and during the accident.

Illustrated accident accounts have a threefold advantage. Firstly, the building process embraced in illustrated accident accounts helps to jog victims' memories and facilitate detailed recall of the facts. Secondly, allo-confrontations-based usage of illustrated accounts with the victim's colleagues allows these colleagues to consider their own, as well as the victim's, work activity. Illustrated accident account-based allo-confrontations enable us to compare operators' views of these accidents. Thirdly, these accounts represent supporting 
media for informing and enhancing operator awareness of AOL risk in their occupational situation.

These interviews again began with an open question: operators were asked to comment successively their colleagues' four AOL. A number of directive questions were asked to obtain more detailed data on their perception of these AOL (e.g. "According to you, what had an impact on this accident's occurrence?" "In a similar situation, what would you have done if faced with this risk?" "Why?" "Do you think that this accident was foreseeable? If yes, why?").

Each of the twelve individual semi-directive interviews lasted an average of 90 minutes. Each was analysed based on thematic content. Thematic analysis initially comprised a systematic statement of risk factors and verbal warnings linked directly or indirectly to the relevant AOL risk. Different themes were identified from these data, then used to collect verbal warnings involving each theme. Operators whose verbal warnings were classed under each theme could then be listed to add a quantitative dimension to the qualitative data collection process.

\section{Results}

\subsection{Main AOL risk factors perceived by the twelve assembler-welders}

Most often mentioned AOL risk factors, perceived by the operators, concerned the assembly template, the work performed and the working conditions (table 1). Problems associated with template design (especially height), balance instability during walking over templates, tidiness problems, missing or damaged planks, welding torch handling problems and those relating to use of certain operating procedures were most frequently referred to. Tiredness adversely 
affecting attentiveness also featured strongly amongst factors identified by operators. Other factors, such as the state of the floor, personal equipment/clothing available to operators, etc. were also mentioned, but much less frequently. Risk factors quoted by assembler-welders belonged to different work situation components (physical, environmental, personal, organisational), bearing witness to the variety and complexity of these accidents.

\section{[Insert TABLE 1]}

A number of operator-identified main AOL risk factors are illustrated below by extracts from verbal accounts and explanations given by the interviewer. In general, walking on the template was perceived as dangerous with respect to the risk of balance disturbance. As one operator claimed, "The bloke who's not used to it soon comes a cropper!" All the assemblerwelders were effectively liable to catch their foot in a template or chassis part. Furthermore, they walked in a state of precarious balance, especially because of the width of the crossbeams, approximately $10-15 \mathrm{~cm}$ wide steel bars, and because of their possible instability prior to stitching (spot welding).

Eight operators out of the twelve believed that working hastily could be a cause of AOL. However, they noted that this was not linked to any completion time-related pressure, but rather to the fact that they wanted to work fast: "You're in a hurry, you want to work fast, you're going to rush a bit and then you can slip. You're in a hurry because you are overkeen”. 


\subsection{Characteristics of the four AOL provided by victims and colleagues}

Two of the four AOL studied led to days lost and occurred when climbing down from the template. Operators were walking over the template carrying their tools in the case of the two AOL with no days lost.

These four AOL all occurred in the morning and three of the operators who sustained an AOL out of four worked on the morning shift ( $2 \times 8 \mathrm{~h}$ work cycle). They took place on two out of the seven templates. In the case of three out of the four AOL, the template structure and arrangement were called into question by the victims (height, no steps, no planks, chassis components to be stepped over).

The first accident took place on a template, on which work was being performed partly on the knees. The accident occurred at 10.45 am on a Friday. The operator was working the morning shift (4.00 am - 12.00 noon). This operator usually worked on other templates, but he was allocated to this template because of chassis demand. The operator stated that this was a common situation. His colleague and he had just finished the chassis. The accident occurred when stepping down from the template. The operator was on the supporting truss, towards the rear of the template, and he jumped down. He had nothing in his hands. He neither saw nor thought about the hole in the floor and he twisted his ankle. This accident gave rise to days lost for a month.

Concerning comments of victim's colleagues, six out of eight operators emphasised the fact that jumping down was dangerous and that it was better to step down "gently" from templates to prevent any AOL risk. However, five out of eight operators used fairly frequently this more dangerous method of jumping down from a template. 
The method of stepping down from templates was linked to the physical condition of operators, especially in relation to their age and length of service at the company: "That must have been a young bloke because those with 30 years company experience don't jump" or "Hey, I'm older now...I'm not as supple as before... We don't jump down in there like we used to”.

The fact that they wanted to avoid possible pains was also a reason for the care taken by some operators when stepping down from templates: "I don't jump; I don't want to break my back”.

According to the latter operators therefore, the safest way of stepping down was as follows: "You step over, you park your backside on the thing and then you climb down gently. You must first ensure you put your feet on stable components”.

Three out of eight operators believed that the accident was partly caused by the "speed" at which this person was working: "He jumped to go faster". This haste was not explained in terms of time-related pressure, but in relation to the fact that the operator "jumped because he wanted to".

According to one operator, jumping or stepping down from templates was also associated with the size of people because a person "puts his foot on the jack pressure cylinders", but he added that the possibility of using this method "depends on the person being small".

Habit was also referred to as a possible factor in this accident: "He forgot there was a hole there. We have our habits. We know we mustn't put a foot there". The operator explained in greater detail that working by habit led to carelessness and that one forgot potential sources of accident risk, even if one was aware of them.

Possible presence of filings (metal particles) on the floor could also have an impact on AOL occurrence (risk of slipping) according to one of the operators. 
Another operator thought that the injured operator may have suffered the "late morning tiredness" that he himself felt when working the morning shift.

The second accident occurred on a template, on which work was largely performed on the knees, at 8.00 am on a Wednesday morning. The operator was working alone on the day shift (7.00 am - 3.00 pm).

The operator stated that the situation was usual. He was leaving the template to go and collect bumper overriders. The stepping down height was approximately $80 \mathrm{~cm}$.

The accident took place when stepping down from the template. When putting his foot on the air hose to be able to get down, his foot slipped and jammed between the air hose and the welding torch generator rail. This operator therefore fell forward and suffered a sprained ankle. This accident gave rise to days lost for a month.

The explanations provided by victim's colleagues for occurrence of the second accident related to the method used by the injured operator to step down from the template: "I wouldn't have placed my foot like that. It's the bloke's fault", or "He was unlucky. If you don't look where you put your feet, it can happen". In this case, the victim was therefore perceived as a central component determining AOL occurrence.

One operator provided a possible clue to understanding this accident: "I know that if you stay too long on your knees, your legs hurt when you stand up and you don't feel them properly". According to this operator, postures adopted on the template could have an impact on balance control at certain moments.

The third accident occurred on a template at 9.00 am on a Thursday. The operator was working the morning shift (4.00 am - 12.00 noon). 
He had just adjusted the cross-beams and was spot-welding them. This was a usual work situation. He was carrying his hammer, cold chisel and set-square and he was wearing a rolled-up welding mask on his head.

The accident took place when the operator was walking over the template: at the fifth or sixth cross-beam, he moved one foot forward to put it on the cross-beam, but misjudged the distance and finally put it down in front of the cross-beam. He therefore fell across the crossbeam without a plank to retain him. The gap beneath the cross-beams was approximately $1.20 \mathrm{~m}$ high. The planks, which had been installed there, were insufficient in number. This accident did not lead to days lost.

The victim's colleagues stated that walking strategies differed. People who considered it dangerous to walk on the cross-beams adopted a strategy involving the chronological order, in which they installed the chassis parts: "I sometimes see them fix the cross-beams first and then do the suspension. I don't work like that. I do the suspension first because cross-beams are dangerous when you walk on them" or "It's easier to fit the suspension first and then the cross-beams because you don't run the risk of tripping in the cross-beams. At least, in the suspension area". Other operators thought that this third accident was more connected with the fact of working by habit: "He believed there was a cross-beam underneath him, that's habit. He thought he would put his foot on the cross-beam".

Another identified risk factor concerned the carrying of tool during walking. Some operators in fact avoided walking with their tools in their hands: they put them down on the runner before stepping over the suspension brackets to avoid falling.

Walking over the template with a welding mask on the head was similarly considered dangerous insofar as the welding mask tended to drop down when the "stay" holding it up loosened. 
The fourth accident happened on a template at 7.50 am on a Tuesday. The operator was working the morning shift (4.00 am - 12.00 noon) with his colleague. This operator worked more frequently on a template other than the one on which the accident occurred. He stated that the situation was usual.

The operator had just finished stitching the trailer landing gear cross-beam and was walking towards the first suspension bracket. In his hands, he was holding his welding torch, hammer, chisel, set-square and pliers. He was also wearing his welding mask in a raised position on his head. He was walking on the continuous cross-beams. The cross-beams, on which he had to step, were approximately $80 \mathrm{~cm}$ wide.

It was when stepping over a template component that the operator caught his foot (two small projecting objects). He therefore could not place his foot properly on the cross-beam. There was an empty space between the continuous cross-beams and the template. The operator therefore fell into this empty space and grazed his thigh on the edge of the crossbeam. He had no time to react because everything happened so quickly. Moreover, he was carrying his tools, which prevented him from recovering balance. This accident did not lead to days lost.

"Carrying his tools.... It's the same old story... With the brackets we had before, we had no trouble." The fact that the injured operator was walking with tools in his hands was again raised. This colleague mentions "brackets" and this refers to the welding torches. The templates were not arranged in the same way before the building renovation work. Previously, the welding torch brackets could be positioned at height, which prevented their hoses from snagging in template or chassis components.

An operator explained his method of working in terms of tools: "There's a hollow in the [suspension] bracket, so hey, I put the set-square there and the hammer in there, it's a sort of 
corner. They won't fall any more. After you've been caught out a few times, you educate yourself'. He in fact placed his tools on the suspension bracket before walking. Tools could not fall at these locations and, if they did, the operator would have to climb down from the template if they had fallen on the ground or he would have to try to extract them from the pit, in which they could have fallen.

Another operator described his way of proceeding: "I try not to step over too much. I go round the outside, whilst staying on top of the template. I'm not big, so I can also pass underneath". This operator seemed to be more aware of the fact that the injured operator had stepped over a template member and he avoided doing this himself. Here, one find the idea in which anthropometrical data, such as operator size, can have an impact on opting for a work practice.

The problem of missing planks at certain places on the template was again referred to here: "We've already asked them to provide planks". It would seem that the situation remained unchanged, despite the fact that all the assembler-welders and their immediate superiors were aware of this problem.

\subsection{AOL and work practices}

\subsubsection{Work practice variability: a link with accidents on the level?}

Work performed is a theme which emerged as a class of AOL factors. Indeed nine of the twelve operators quoted AOL factors connected with work performed. Work practices more or less riskier in terms of the probability of AOL occurrence were identified from the alloconfrontations. Some operators referred to the walking activity (e.g. putting one's feet on stable locations), stating that work practices had an impact on their way of walking and the 
passageway they used. Others described other activities which had an impact not only on operator walking frequency and consequently on the frequency of walking at risk (e.g. preparing parts to avoid climbing onto and down from the template), but also on the safety of upcoming walking (e.g. putting parts on the side of the template to avoid walking on them). They were not necessarily implemented to decrease the AOL risk, but in fact appeared to have an impact on the probability of this type of accident occurring (e.g. moving underneath the suspension bracket instead of stepping over it to avoid tiredness). Implementation of each of these work practices determined operator walking frequency (especially in anticipation of tasks to be performed and in walking optimisation), passageways used and ways of walking (e.g. walking when carrying tools and/or parts). Altogether, 30 work practices affecting AOL risk were identified from the interviews. Of these, seventeen referred to walking activity and thirteen referred to other activities determining frequency of walking at risk or safety of upcoming walking. Table 2 presents some of these work practices. Those describing walking activity were either precautions taken whilst walking at risk (e.g. sitting on template to get down) or dangerous practices (e.g. jumping to the floor). Other work practices were indirectly linked to safety as illustrated by the two following examples. Work practice involving installation of only few cross-beams on the template not to hinder walking over the template, could be considered an indirectly safe practice. Conversely, work practice involving collection of a few parts in passageways and the remainder later increased the frequency of walking at risk and could be considered an indirectly dangerous practice.

The question is which factors have an effective impact on operator implementation of such work practices.

[Insert TABLE 2] 


\subsubsection{Factors affecting work practice adoption}

Analysis of verbal warnings in relation to AOL-related work practices allowed us to suggest a number of factors, which the operators considered to have influenced their adoption of these work practices (table 3). The adopted work practices depended on several factors, which may have been related to characteristics of the relevant technical systems (template design) and operator physical conditions (pain, tiredness). These were adjusted, in particular by working conditions, operator anthropometric characteristics (size) with respect to performance conditions of the task to be undertaken, and the leeway available to the operator in relation to his knowledge (experience, training) and work situation (equipment risks and availability).

\section{[Insert TABLE 3]}

The following verbal account extracts illustrate the part played by some of the factors identified by operators as determining the adoption of work practices more or less at risk with respect to AOL.

Concerning avoidance of template-based walking, perceived to be tiring and arduous, one of the operators stated that: "There are tricks that [he has] seen performed and [that he performs] otherwise to avoid tiring [himself]. [He] anticipates, [he'll] possibly spend more time on one thing and less time on another to save his energy". More specifically, the second operator explained: "We organise ourselves to put what we don't use much on the sides and what we do need, well, we keep to hand. So, we've got everything right there [on the template]. We don't have to climb up or down. Once we're there, we'll take an hour, an hour and a half, to do the middle. [...] At the beginning you'll get on and off the template 50 times 
for sure. But, once you've done that for a week, after climbing up and down all day, well, you know roughly what you have to do and you prepare everything you need". These accounts, show the significance of the 'tiredness' and 'experience' factors, which were determining in the implementation of certain work practices such as, for example, preparing the parts and tools required for chassis assembly. This preparation practice sometimes failed due to equipment-related risks, such as unavailability of these parts right from the start of assembly because of delays in their manufacturing.

Some operators (the three longest serving) stated that, with age, they did not work in the same way. Their statements can be summarised by an explanation provided by one of them: "After all, I'm older now. Before, we used to jump in there, we weren't careful, but now I try [to walk] on the floor as much as possible. If I'm in front, I get down and bring everything I need. If I want to go behind, I walk round and then get up onto the template at the back. I avoid walking too much over the template, it prevents me damaging myself. I'm less supple than before. You don't jump in like you used to do before. You try to put as many tools and parts as possible near to hand to keep jumping down to a minimum. I used to do it like them 20 years ago; I used to jump right in there... You see them sometimes... I tell him to "be careful, you catch yourself and you'll fall'. When you want to climb up or down, you're always in a bit of a hurry to go and collect a part or whatever". The "age", "pains" and "experience" factors appeared several times in the statements of these three people as determining in relation to choice of their work practices. The "pains" factor did not only appear in the verbal accounts of the oldest operators because it was quoted by eleven out of twelve operators. These pains were located at the knee or in the back and were linked to operator postures and walking, which were themselves determined by template design. 
A more unexpected factor was also referred to during these interviews, namely "operator size". Stepping over template components or suspension brackets, represented an AOL risk according to the operators, but the choice of stepping over or not resided more in the fact that the operators concerned can be tall or short. Operators stated that size was also related to jumping down from the template because the components, on which operators could put their feet when they wanted to jump down from the template, were relatively low. Operator size therefore seemed to influence adoption of specific work practices according to the verbal accounts collected during these interviews. The smallest operators effectively stressed the fact that it was difficult to step over template components and climb down from the template: "When you go from one [suspension] bracket to another, either you have long legs and you try to step over those things or, you're like me and it doesn't work".

The variety of work practices used can therefore be explained by combinations of factors specific to each operator and to the work situation, in which the operators walk.

\section{Discussion}

The study findings echo those of the literature.

The first observation is a product of the systemic nature of AOL. In their study of the British postal population, Bentley and Haslam (1998, 2001), and Haslam and Bentley (1999) highlighted effectively that AOL occurrence resulted from combinations of factors concerning the various work situation components (organisation, physical and social environment, equipment and individual). For example, the state of the floor, lighting of the passageway, lack of awareness of the AOL risk, tiredness felt by employees, etc., were so many factors that combined and led to the AOL. The present study of assembler-welders also found factors belonging to these various work situation components (e.g. unavailability of parts at the start 
of chassis assembly, obliging operators to undertake more frequently risky walking on account of organisational problems, untidy tools, floor condition, operator tiredness, etc.).

Consequently, the practical prevention measures which resulted from this study were about the various situation components. Amongst these recommendations, a number were implemented by the company. First of all, overhead travelling controls without cables were placed at the operators' disposal; a measure which allowed them to walk on the template without sustaining the risk of balance disturbance by cables being caught in the template or chassis parts. Then a warehouse was installed, improving stock control and chassis part organisation. On the one hand, the risk of tripping on a part when walking on or around the template was reduced, and the reorganised warehouse made it easier to make parts available to the operators' at the start of chassis assembly. Operators could thereafter prepare parts required for chassis assembly and avoid climbing onto and down from the template, movements which are likely to cause AOL. The third prevention measure adopted was the setting up of parts supply system based on parts being transferred directly to the templates in kit form. This measure enabled the operators to reduce their movements by avoiding the need to collect parts themselves. They could again prepare parts required for chassis before starting its assembly, thereby avoiding climbing onto and down from the template. The company was also considering setting up an AOL risk awareness programme for recruits.

The second observation concerns conditions of OA, and more specifically AOL, occurrence. Rousseau $(1992,1993)$ has noted that OA occurred principally when working conditions are, a priori, usual: operators are confronted by risk factors familiar to them and manage to ensure safety, until the day when an accident occurs under circumstances which, nevertheless, seem usual working conditions. 
In this case, four AOL were studied, in particular by interviewing the operators who sustained these accidents. Work situations, in which accidents occurred, were usual for these four assembler-welders. According to them, the fact that they were working on a template, which was less familiar to them, was also a usual work situation because they all have to work on different templates, depending on the chassis orders they receive. Even though there was an effective presence of certain AOL risk factors in these accident situations, these same risk factors were frequently present in the work situation and, prior to the event, had never caused accidents.

A third observation highlights the role of implemented work practices in AOL occurrence. Bentley and Haslam $(1998,1999,2001)$ further explained that British postal workers adopted work practices involving AOL-related risk. Their study revealed that adopting risk-related work practices was especially linked to their work organisation, which effectively encouraged them to act less safely: to finish their working day earlier, they took shortcuts across more uneven ground, and read addresses on envelopes whilst walking. During interviews, these postal workers stated that they were aware of the risks involved in their work practices, but they perceived them as more acceptable than the time-wasting associated with a safer work practice. The present study found that work organisation impacted on the adoption of work practices involving greater risk. In the assembler-welder working situation, part supply problems linked to organisational deficiencies in the logistics sector obliged operators to adopt a work practice involving risk. Indeed, when available, parts could be prepared at the start of chassis assembly. Otherwise, operators had to climb more often onto, or down from, a template to collect parts (climbing down from templates being particularly unsafe).

The impact of training received by operators in terms of both safety and ways of performing the required task has also been put forward by Bentley and Haslam (1998) and thereby 
constitutes a fourth observation. These authors suggested that training of a new recruit by a more experienced peer could encourage transmission of bad, potentially risky working habits and this was indeed the case at the company involved in our study. During interviews with the twelve operators, eight of them referred to the fact that this training method could induce transmission of unsafe, yet possibly "quicker" or "more practical” work practices.

During the twelve interviews, it was noted that all the operators referred to implementation of work practices which either increased or decreased the AOL risk. These operators adopted work practices, which allowed them to perform their task whilst keeping their balance. Certain work practices were intentionally implemented to keep balance and others had an impact on AOL risk without being implemented with this intentional aim. In some situations, operators could also be required to "take risks". Implementation of work practices involving greater AOL-related risk depended on all the determining factors, as widely different as operator size, tiredness, parts unavailable at the start of chassis assembly, knowledge of work to be performed and of the template, etc.

Safe work practices identified in this study can be compared with what Cru and Dejours (1983, 1997) considered to be elements of care-related know-how: procedures allowing operators to protect themselves from risks and which are integrated into their occupational know-how. There were several forms of safe work practice and some were required by the company, whilst others represented informal practices. Rousseau (1999) has stated that an informal safety practice comprises "any action, which is performed at the initiative of the operator(s) and contributes to increasing safety at both a general (e.g. workplace cleanliness) and specific (particular work operation) level". This author provided the following example of an informal safety practice: this involves a "practice limiting the number of [electrical] pole ascents and thus the risks of falling from a height. During equipment preparation, therefore, 
[lineman] crews stick a coloured adhesive tape on the neutral conductor to prompt its identification, when connecting up at the top of the pole. Similarly, an inventory is made of the tools required for performing the work and they are placed in the operator's tool bag or in the truck elevator cradle". These practices are specifically characterised by the fact that they are integrated into operator know-how and that they are difficult to observe. According to Rousseau (1993), "a crew using this type of practice gives intuitively the impression of work "well done", "finely tuned"; this impression due, in reality, to a proliferation of these practices".

Informal safety practices also echo one of the three functions ensured by the operator (production, recovery and prevention), namely the prevention function (Faverge, 1967). By anticipating, by projecting himself into the future, the operator becomes "architect of system reliability" through his actions. This allows him "to raise not only the level of safety, but also the quality of work and service" (Rousseau, 1993).

The characteristics of the conducted study contribute to both its significant and limitations. Its first limitation relates to the small study population, which is not uncommon in such case studies. Risk factors quoted by operators were specific to a particular work situation. However, it can be hypothesised that certain work practices do effectively have an impact on the walking frequency, passageways used and ways of walking in every occupational situation. Another issue is generalisation of the factors affecting work practice selection. For example, it can be inferred that in a situation more closely similar to daily life (e.g. walking on stairs vs. walking on templates), the weight of work experience amongst the factors affecting the choice of a work practice would be lower than in the study situation. 
A second limitation of our study is associated with the methods used, mainly operator interviews. Data acquired, using the operator interview approach, were qualitative and subjective, and this may effectively represent a study limit. However, comparison of operator views on the four AOL, which occurred, was a means of more fully assessing and thus partly overcoming the method's subjectivity.

Implementation of interviewing methods also requires us to know whether there are biases intrinsic to verbal accounts recorded during an accident analysis study. Kouabenan (1999, 2002) has noted that attribution of accident causality varies, depending on whether the victim or his work colleague is interviewed. He stated (1999) that "accident victims attribute [their accident] more to external factors, whilst their colleagues and foremen attribute them to factors internal to the victim". Verbal accounts obtained at the interviews conducted during our study appear to be consistent with this statement. During allo-confrontations based on illustrated accounts of the AOL, the colleagues of the four operators who sustained an AOL stressed that the victims had adopted risk-related work practices. As for the four victims, they reported accident factors external to themselves (walking instability, holes in floor, etc). Even though this bias exists, if one takes it into account and conducts interviews of both accident victims and their colleagues, a set of data can be derived offering us the least abbreviated view possible of the occurrence of these accidents.

Accident analyses have been conducted within the scope of this study. Accident analysis can be defined in the same way as a case study, i.e. an analysis, that aims to "show how the case production conditions are built up: characterisation of this structuring is indeed the basic feature of the case study" (Leplat, 2002). In this case, the accident is a situated event forming an analysis unit, which falls within a given context [internal, i.e. related to the characteristics of the subject, and external, i.e. related to the physical, technical, organisational, etc. 
conditions (Leplat, 2002)]. Resetting the particular accident case in the wider framework of the usual work situation may enable us to tackle this problem from a new angle: the central issue raised being no longer "How and why the accident occurred?" but "How does the operator usually perform his task?" Analysis would no longer focus mainly on the accident, but rather on the "usual" situation, because its study could help us to understand why one way, amongst all the various ways of performing a task, and therefore one work practice is chosen in preference to another. What is the impact of this choice on the probability of an AOL occurring? In this way, Leplat (2002) states that "in becoming a story" and therefore in resituating the accident in a usual situation, "the case throws light on its development, the genesis of its production". Moreover, focusing our future research on activity analyses would allow us to overcome the subjective nature of data acquired exclusively by interviewing.

\section{Future prospects and conclusions}

This study shows that AOL can be perceived as a clue to the malfunctioning of a system (Leplat, 1985); the system corresponding here to the work situation in its environmental, organisational and social aspects, including the operator.

This malfunction within the system is prompted by implementing a work practice affecting the ability of the operator to perform the required task, whilst keeping his balance. In this, the study of work practice is a key factor in understanding AOL insofar as implementing a work practice reflects the compromise, adopted by an operator, between the task as required, the constraints to be confronted by him, the resources at his disposal and his own expectations [Hale and Glendon, (1987), Rabardel, (1995, 2005), Rabardel and Bourmaud, (2005)]. 
The preceding statement therefore prompts reflection not only on the determining factors, which lead to adoption of a more or less risky work practice, but also on the range of work practice options for operators in a given situation. A study of the range of work practice options for all operators and of these work practices themselves can help us to understand how operators succeed in performing their task, whilst keeping their balance, in situations in which balance is threatened. Such a study could help to understand why a combination of factors turns out to be accident-causing. Work situations, in which the studied AOL arise, were effectively considered usual by each of the AOL victims encountered. These situations integrate AOL factors without an AOL systematically occurring. Furthermore, Hoffman et al. (1998) states that "knowledge of the selection options and, thus, of those that are discarded often shed light on the motives of an action".

Analysis of "undisturbed" activity will therefore occupy a central position, from which work practices available or unavailable to operators will be studied in subsequent research. 


\section{Acknowledgements}

We wish to thank the CRAM Nord Est regional health insurance fund for its assistance in seeking study sites. We also thank the company, at which this study was conducted, and especially the persons in charge of safety, the operators, who took part in this research, and their immediate superiors. 


\section{References}

BENTLEY, T.A., 2008. The role of latent and active failures in workplace slips, trips and falls: an information processing approach. Applied Ergonomics, Article in Press.

BENTLEY, T.A. and HASLAM, R.A.,1998. Slip, trip and fall accident occurring during the delivery of mail. Ergonomics, 41, 1859-1872.

BENTLEY, T.A. and HASLAM, R.A., 2001. Identification of risks factors and countermeasures for slip, trip and fall accidents during the delivery of mail. Applied Ergonomics, 32, 127-134.

BENTley, T.A., TAPPIN, D., MOORE, D., LEGG, S., ASHBY, L., PARKER, R. 2005. Investigating slips, trips and falls in New-Zealand dairy farming sector. Ergonomics, 48, 1008-1019.

BENTLEY, T.A., HIDE, S., TAPPIN, D., MOORE, D., LEGG, S., ASHBY, L., PARKER, R. 2006. Investigating risk factors for slips, trips and falls in New-Zealand residential construction using incident-centred and incident-independent methods. Ergonomics, 49, 6277.

BOWMAN, R., 2007. Where to next with slip resistance standards ? [online] Available from : http://www.cmit.csiro.au/vb2/345/67/index.htm [Accessed 28 November 2007] 
CNAMTS (Caisse Nationale d'Assurance Maladie des Travailleurs Salariés), 2005. Statistiques nationales des accidents du travail, des accidents de trajets et des maladies professionnelles (Années 1977-1987-1997-2005). Paris : CNAMTS.

CRU, D., 1997. Les politiques de prévention des risques professionnels : valoriser les savoirs collectifs. Entretien avec Damien Cru. [online].

Available from : http://www.alencontre.org/EdPage2/p2_trv_cru.html.

[Accessed 28 November 2007]

CRU, D. and DEJOURS, C., 1983. Les savoir-faire de prudence dans les métiers du bâtiment. Les Cahiers médico-sociaux, 3, 239-247.

DAVIES, J.C.,KEMP, G.J., FROSTICK, S.P., STEVENS, G., MANNING, D.P., 2003. Age and gender in underfoot accidents. Safety science, 41, 65-76.

DEROSIER, C., 2005. La prévention des accidents de plain-pied : comprendre la dynamique existant entre contraintes situationnelles et ressources individuelles. Mémoire de DEA. Université Paris 8.

FAVERGE, J.M., 1967. Psychosociologie des accidents du travail. Paris : PUF.

GAO, C., ABEYSEKERA, J., 2004. A systems perspective of slip and fall accidents on icy and snowy surfaces. Ergonomics, 47, 573-598. 
GAUCHARD, G., CHAU, N., MUR, J.M., PERRIN, P., 2001. Falls and working individuals : a role of extrinsec and intrinsec factors. Ergonomics, 44, 1330-1339.

GAUDEZ, C., LECLERCQ, S., DEROSIER, C., 2006. National Statistics of occupational accidents on the level in France. IEA Congress, 10-14 July, Maastricht.

HALE, A.R. \& GLENDON, A., 1987. Individual behaviour and control of danger. New York: Elsevier.

HASLAM, R.A. \& BENTLEY, T.A. (1999). Follow-up investigations of slip, trip and fall accidents among postal delivery workers. Safety Science, 32, 33-47.

HOFFMAN, R.R., CRANDAL, B., SHADBOLD, N., 1998. Use of the critical decision method to elicit expert knowledge : a case study in the methodology of cognitive task analysis. Human Factors, 40 ( 2), 254-276.

HSE, 2007. Health and safety statistics 2005/06 [online]. Health and Safety Executive. Available from : http://www.hse.gov.uk/statistics/index.htm [Accessed 10 October 2007]

KINES, P., 2003. Case studies of occupational falls from heights : cognition and behavior in context. Journal of Safety Research, 34, 263-271.

KOUABENAN, D.R., 1999. Explication naïve de l'accident et prévention. Paris : PUF. 
KOUABENAN, D.R., 2002. Décision, perception du risque et sécurité. In J.L. Bernaud, C. Lemoine, eds., Traité de psychologie du travail et des organisations. Paris : Dunod. , 279321.

LECLERCQ, S., 1997. La prévention des chutes de plain-pied, bilan, perspectives, NST 157, INRS.

LECLERCQ S., 2002. Instruction de la thématique : prévention des chutes de plain-pied en situation professionnelle. NST 0217.

LECLERCQ, S., 2005. Prevention of so-called "accidents on the level" in occupational situations : a research project. Safety Science, 43 (7), 359-371.

LECLERCQ, S. and THOUY, S., 2004. Systemic analysis of so-called "accidents on the level" in a multi-trade company. Ergonomics, 47(12), 1282-1300.

LECLERCQ, S. and TISSOT, C., 2004. Les chutes de plain-pied en situation professionnelle

- Circonstances de chutes particulièrement graves à travers l'analyse statistique de 459 cas. ND 2206-194-04. Paris : INRS.

LEPLAT, J. (Eds.), 1985. Erreur humaine, fiabilité humaine dans le travail. Paris : A.Collin.

LEPLAT J., 2002. De l'étude de cas à l'analyse de l'activité. Pistes, 4 (2). 
MANNING, D.P., AYERS, I., JONES, C., BRUCE, M., COHEN, K., 1988. The incidence of underfoot accidents during 1985 in a working population of 10000 Merseyside people. Journal of Occupational Accidents, 10, 121-130.

MOLLO, V. and FALZON, P., 2004. Auto- and allo-confrontation as tools for reflective activities. Applied Ergonomics, 35 (6), 531-540.

RABARDEL, P., 1995. Les hommes et les technologies, une approche cognitive des instruments contemporains. Paris : Armand Colin.

RABARDEL, P., 2005. Quels pouvoirs d'agir pour quels acteurs ergonomiques ? Actes des journées de Bordeaux sur la pratique de l'ergonomie. Mars 2005.

RABARDEL, P. and BOURMAUD, G., 2005. Instruments et systèmes d'instruments. In : P. RABARDEL and P. PASTRE, eds. Modèles du sujet pour la conception, dialectique activités développement. Toulouse : Octares, 211-229.

ROUSSEAU, C., 1992. La gestion des risques par les opérateurs - Le cas des monteurs électriciens. Sécurité et Médecine du Travail, 4.

ROUSSEAU, C., 1993. Gestion de la sécurité par l'opérateur - Mise en évidence de conduites sécuritaires au cours d'une activité de chantier. Cahiers de notes documentaires, 151.

ROUSSEAU, C., 1999. De l'étude du comportement à celle des situations de travail. Performances humaines et techniques,101, 71-76. 
WEBSTER, T., 2000. Workplace falls. Compensation and working conditions. [online] US Department of Labour, Bureau of Labor Statistics.

Available from: http://www.bls.gov/opub/cwc/archive/spring2000art4.pdf

[Accessed 28 November 2008] 
Table 1. AOL risk factors perceived by assembler-welders and factors directly implicated.

Table 2. Work practices for assembler-welders in relation to AOL risk.

Table 3. Factors quoted by assembler-welders as affecting choice of work practices, which are more or less at risk with respect to AOL.

Figure 1. Operator applying spot weld at joints between chassis cross-beams and edge; parts previously positioned on the template by this same operator. 
Table 1. AOL risk factors perceived by assembler-welders and factors directly implicated.

\begin{tabular}{|c|c|}
\hline Elements primarily implicated and perceived AOL risk factors & $\begin{array}{l}\text { Number of operators } \\
\text { out of } 12 \text {, who } \\
\text { mentioned this factor }\end{array}$ \\
\hline $\begin{array}{l}\text { Template (template height, damaged planks, missing planks, template structure like } \\
\text { hole and member height) }\end{array}$ & $10 / 12$ \\
\hline Work performed (carrying tools, route followed and way of walking) & $9 / 12$ \\
\hline Work performed and production organisation (work rate: high, imposed or not) & $8 / 12$ \\
\hline $\begin{array}{l}\text { Operator and working conditions (tiredness: general and of lower limbs; care: } \\
\text { little care given to maintaining balance and to resulting work practices) }\end{array}$ & $8 / 12$ \\
\hline $\begin{array}{l}\text { Template and welding torch (gap between generator rail and air line: foot can be } \\
\text { trapped) }\end{array}$ & $7 / 12$ \\
\hline $\begin{array}{c}\text { Template and chassis (walking instability linked to cross-beam, rail, template } \\
\text { structure) }\end{array}$ & $6 / 12$ \\
\hline Welding torch (location of the welding torch bracket) & $5 / 12$ \\
\hline Operator clothing (shoelaces, loose clothing, wearing welding mask) & $4 / 12$ \\
\hline $\begin{array}{l}\text { Tidiness (Torch and grinder hoses in passageways, parts left in passageways, } \\
\text { tools in template, parts in template) }\end{array}$ & $4 / 12$ \\
\hline Chassis (chassis parts: tripping on edge) & $3 / 12$ \\
\hline Overhead travelling cranes (cables of the overhead travelling crane control) & $3 / 12$ \\
\hline Floor (hole in the floor) & $1 / 12$ \\
\hline
\end{tabular}


Table 2. Examples of work practices in relation to AOL risk considering the activity performed.

\begin{tabular}{|c|c|c|}
\hline \multicolumn{2}{|c|}{ Work practice concerning... } & Description of work practice (direct statement or as reported by interviewer) \\
\hline \multirow{12}{*}{$\begin{array}{l}\text { Walking } \\
\text { activity }\end{array}$} & $\begin{array}{l}\text { Walk over the template } \\
\text { with a welding torch }\end{array}$ & $\begin{array}{l}\text { "Sometimes we step over [a member], which then snags if it has passed behind something. So we make sure we can pull it, whilst } \\
\qquad \text { walking forwards at the same time, so as not to lose balance or have to walk backwards". }\end{array}$ \\
\hline & \multirow{3}{*}{$\begin{array}{l}\text { Put one's feet on the } \\
\text { template (stable locations) }\end{array}$} & "I walk on the cross-beams rather on the edges because they move less" \\
\hline & & "You must avoid putting your foot on the trailer landing gear cross-beam, if it isn't stitched" \\
\hline & & $\begin{array}{l}\text { "When we make container low-slung chassis, there's a big block right there, which is raised, and I always put my foot on that. It's } \\
\text { a point of reference I've given myself" }\end{array}$ \\
\hline & Climbing onto the template & "It's pretty high all the same; you support yourself with your arms; it's more convenient with the arms" \\
\hline & \multirow{4}{*}{$\begin{array}{l}\text { Getting down from the } \\
\text { template }\end{array}$} & Some jump directly to the floor. \\
\hline & & Others sit on the template to get down. \\
\hline & & $\begin{array}{l}\text { Others, again, use template and chassis parts as rungs, on which they put their feet (e.g.: "I put my foot flat on the air hose to get } \\
\text { back down") }\end{array}$ \\
\hline & & "I look to see where I'm going to climb down because, with the space we have, it's not wide, it's narrow and quite high" \\
\hline & \multirow{3}{*}{$\begin{array}{l}\text { Passing from one } \\
\text { suspension bracket to } \\
\text { another (to scribe, position }\end{array}$} & They go underneath (only for small operators). \\
\hline & & Operators step over the first suspension bracket. \\
\hline & & They climb down from the template and take advantage of this to pick up a part and climb back at the second suspension bracket. \\
\hline
\end{tabular}




\begin{tabular}{|c|c|c|}
\hline & and spot-weld parts) & They walk along the runner flat-iron or on the edge of the template. \\
\hline \multirow{3}{*}{$\begin{array}{l}\text { Activities } \\
\text { which have } \\
\text { an impact }\end{array}$} & Installing cross-beams & $\begin{array}{l}\text { Some of them prefer to install all (35) cross-beams at the same time. Others think that arranging all the cross-beams is a nuisance } \\
\text { because they hinder their walking over the template, when assembling the suspension. The latter operators therefore only have } 10 \\
\text { cross-beams before assembling the fifth wheel plate and only add other cross-beams after chassis assembly. }\end{array}$ \\
\hline & \multirow{3}{*}{$\begin{array}{l}\text { Carrying parts in } \\
\text { passageways }\end{array}$} & $\begin{array}{l}\text { Some will get themselves a trolley or wheelbarrow to collect parts. These various ways of getting parts will have an impact on } \\
\qquad \text { both operator tiredness and the amount of walking performed. }\end{array}$ \\
\hline & & Others will collect a few and collect the rest afterwards. \\
\hline $\begin{array}{l}\text { on the } \\
\text { operator }\end{array}$ & & Others, again, will tend to overload themselves to reduce the amount of walking \\
\hline $\begin{array}{l}\text { operator } \\
\text { walking } \\
\text { frequency }\end{array}$ & \multirow{3}{*}{$\begin{array}{l}\text { Preparing parts and tools } \\
\text { required for assembling the } \\
\text { chassis, if there is indeed } \\
\text { preparation }\end{array}$} & $\begin{array}{l}\text { "I prepare all the parts and then I don't get back down; I finish everything. I only go once as a rule. It's already no bad, if you } \\
\text { think } 40 \% \text { about a job.[...] At the beginning, for sure, you'll climb up on and down from the template } 50 \text { times. OK, once you've } \\
\text { done it for a week, after climbing up and down all day, you know roughly what you need and you prepare everything you need". }\end{array}$ \\
\hline safety of the & & As for other operators, they prepare very little their template work: they therefore walk more with their tools in their hands. \\
\hline \multirow[t]{2}{*}{$\begin{array}{l}\text { upcoming } \\
\text { walking }\end{array}$} & & $\begin{array}{l}\text { Other work practices relate to placing chassis parts, which will be used: some operators anticipate their walking and place parts so } \\
\text { that they don't obstruct walking on the template. }\end{array}$ \\
\hline & $\begin{array}{l}\text { Assembling and welding a } \\
\text { chassis working in pairs }\end{array}$ & $\begin{array}{l}\text { Working in pairs also allows a degree of inter-aid and, because of this, a reduced number of walking onto and away from the } \\
\text { template (when one operator is outside the template, he can pass parts and tools that his colleague might have forgotten to pick up } \\
\text { or that were not available during preparation). }\end{array}$ \\
\hline
\end{tabular}



Table 3. Factors identified by assembler-welders as affecting choice of work practices, which are more or less at risk with respect to AOL.

\begin{tabular}{|c|c|}
\hline FACTORS & NUMBER OF OPERATORS QUOTING THIS FACTOR \\
\hline AGE & $3 / 12$ \\
\hline SIZE & $4 / 12$ \\
\hline TIREDNESS & $7 / 12$ \\
\hline TRAINER, COLLEAGUE & $8 / 12$ \\
\hline PAINS & $11 / 12$ \\
\hline EXPERIENCE ACQUIRED & $12 / 12$ \\
\hline EQUIPMENT-RELATED RISKS & $12 / 12$ \\
\hline TEMPLATE DESIGN & $12 / 12$ \\
\hline
\end{tabular}

Figure 1. Operator applying spot weld at joints between chassis cross-beams and edge; parts previously positioned on the template by this same operator.

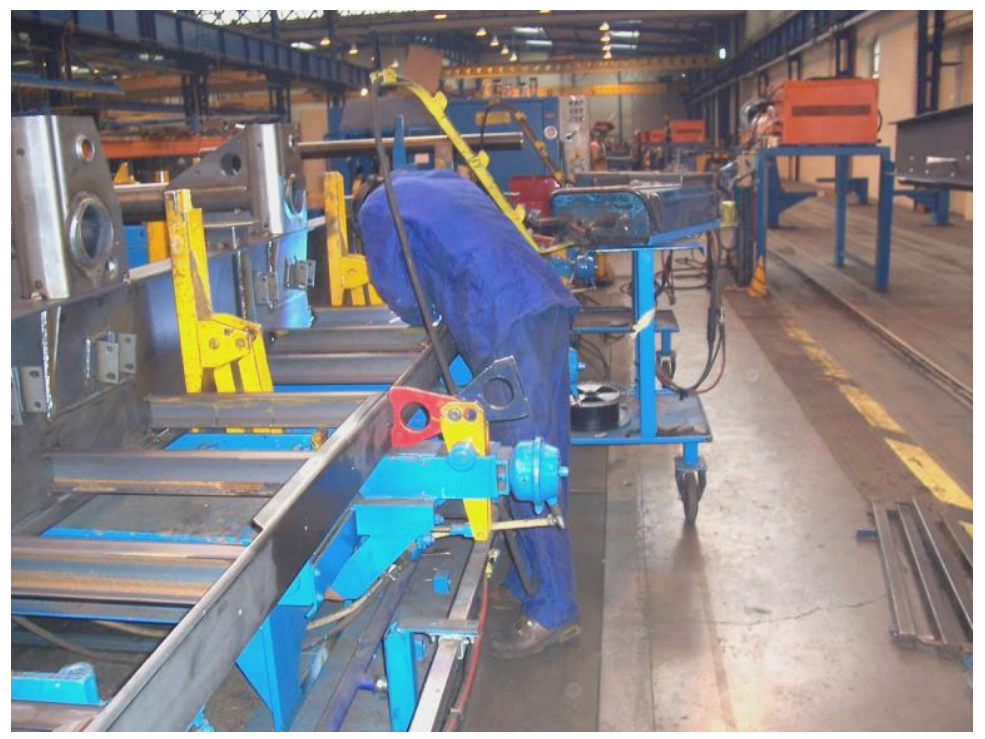

